Article

\title{
A randomized, open-label study to assess efficacy of weekly as- sumption of cholecalciferol versus calcifediol in older patients with hypovitaminosis D
}

\author{
Chukwuma Okoye ${ }^{1}$, Valeria Calsolaro${ }^{1}$, Filippo Niccolai ${ }^{1}$, Alessia M. Calabrese ${ }^{1}$, Riccardo Franchi ${ }^{1}$, Sara Rogani ${ }^{1}$, \\ Giulia Coppini ${ }^{1}$, Virginia Morelli ${ }^{1}$, Nadia Caraccio ${ }^{1}$, Fabio Monzani ${ }^{*}$
}

\author{
1 Geriatrics Unit, Department of Clinical and Experimental Medicine, University of Pisa, Pisa, Italy \\ * Correspondence: fabio.monzani@med.unipi.it; Tel.: +393337733135 (Geriatrics Unit, Department of Clinical and Experi- \\ mental Medicine University of Pisa, Via Savi 10, 56126 - Pisa, Italy)
}

\begin{abstract}
The aim of this single-center, open-label, non-controlled randomized study was to evaluate which formulation of vitamin $\mathrm{D}$ between cholecalciferol and calcifediol is most effective in the treatment of hypovitaminosis D in older adults. Demographic characteristics, clinical history and comprehensive geriatric assessment were recorded at admission. Eligible patients randomly received an equivalent vitamin D supplement either with cholecalciferol or calcifediol from hospital admission to three months after discharge. Among the 140 older patients included (mean age 83 \pm 6.6 , $57.8 \%$ females), 69 received cholecalciferol and 71 calcifediol. The mean plasma values of $25 \mathrm{OH}-$ Vitamin D3 found at the enrollment were $16.8 \pm 9.9 \mathrm{ng} / \mathrm{mL}$ in patients receiving cholecalciferol and $18.8 \pm 13.3 \mathrm{ng} / \mathrm{mL}$ in those treated with calcifediol $(\mathrm{p}=0.31)$. At the 3 -month follow up, the mean concentration of $25 \mathrm{OH}-$ Vitamin D3 was significantly higher in patients treated with calcifediol than in patients treated with cholecalciferol (respectively, $30.7 \pm 8.4$ vs $45.4 \pm 9.8 \mathrm{ng} / \mathrm{mL}, \mathrm{p}<0.001$ ). Supplementation with cholecalciferol or calcifediol results in both cases effective in reaching optimal circulating values of $25 \mathrm{OH}-\mathrm{VitaminD} 3$ in the older patients suffering from hypovitaminosis D. However, supplementation with calcifediol led to average circulating values of $25 \mathrm{OH}$ - VitaminD3 significantly higher (over 50\%) than those obtained with cholecalciferol.
\end{abstract}

Keywords: hypovitaminosis D; cholecalciferol; calcifediol; vitamin D; older patient

\section{Introduction}

Hypovitaminosis D represents a widespread condition worldwide, particularly in the elderly population; it is estimated that about $7 \%$ of the world population is affected by severe hypovitaminosis (25OHD less than $10-12 \mathrm{ng} / \mathrm{mL}$ ), while $37 \%$ of the population has moderate hypovitaminosis (25OHD between $20 \mathrm{ng} / \mathrm{mL}$ and $10-12 \mathrm{ng} / \mathrm{mL}$ ) [1]. There is broad consensus in the literature on how achieving sufficient levels of vitamin $\mathrm{D}$ plays an important role in improving not only bone homeostasis but also muscle performance and physical health in general $[2,3]$. The most used therapeutic strategy in order to reach adequate levels of vitamin D is administering vitamin D supplements, associated with a correct daily intake of calcium, the latter preferably with food [4]. Cholecalciferol (D3) and ergocalciferol (D2) are the most historically used molecules. Recently, calcifediol (25$\mathrm{OHD})$, the form activated by the hepatic enzyme 25-hydroxylase, is also considered a valid therapeutic alternative. The intestinal absorption of cholecalciferol is effective in healthy subjects, while it may be severely compromised in patients with intestinal malabsorption, a condition often found in geriatric patients. On the contrary, calcifediol is 
absorbed very effectively and the difference in intestinal absorption kinetics largely explains its remarkable bioavailability. The purpose of this prospective, randomized study is to evaluate which vitamin $\mathrm{D}$ formulation, between cholecalciferol and calcifediol, is the most effective in treating hypovitaminosis D in older adults.

\section{Materials and Methods}

A single-center, open-label, non-controlled, randomized study was conducted on geriatric patients hospitalized at the Geriatric Unit of the University Hospital of Pisa for acute illness, from May to September 2020. Demographic characteristics and clinical history were collected at admission. Each patient underwent a Comprehensive Geriatric Assessment (CGA), composed of: Cumulative Illness Rating Scale (CIRS) [5], Activities of Daily Living (ADL) [6], Instrumental Activities of Daily Living (IADL) [7], Short Portable Mental Status Questionnaire (SPMSQ) [8], Mini-Nutritional Assessment (MNA) [9] and Exton Smith Scale (ESS) [10]. Body Mass Index (BMI) and Multi-Prognostic Index (MPI) [11] were also recorded. In order to investigate the presence of sarcopenia, the handgrip strength (HGS) test was performed using a hand dynamometer with the dominant hand. Participants were seated with shoulder adducted, elbow flexed to 90 degrees, and forearm and wrist neutral. The highest score of three consecutive measurements was recorded. Exclusion criteria were: i) Subjects who received vitamin D supplementation in the past six months; ii) patients with stage $\mathrm{V}$ renal insufficiency; iii) hepatic insufficiency; iv) hyperparathyroidism, v) malabsorption syndromes; vi) neoplastic disease under treatment were excluded, vii) patients who were unable to give informed consent. The dose of vitamin $D$ supplementation was chosen based on current recommendation ( $20 \mathrm{mcg}=800 \mathrm{UI} /$ day $)$ [12-16]. Therefore, considering that calcifediol is about 3-fold more potent than cholecalciferol [4], eligible patients randomly received a bioequivalent dose of vitamin $\mathrm{D}$ either with cholecalciferol $(10,000 \mathrm{IU} / \mathrm{ml} 70$ drops/week) or calcifediol $(1.5 \mathrm{mg} / 10 \mathrm{ml} 28$ drops/week) during hospitalization and for three months after discharge. Randomization was performed by a physician using coin-flipping procedure. Before starting vitamin D supplementation, baseline blood samples were taken and 25-OH-Vitamin D3, parathyroid hormone, total calcium, calcium ion, phosphate, albumin and creatinine were measured. Three months after discharge, patients were re-evaluated at the geriatric-endocrinology ambulatory where they underwent a HGS test and blood tests. The study protocol complied with the Declaration of Helsinki and was approved by the Pisa University Hospital Ethic Committee. Written informed consent was obtained from all patients included in the study.

\section{Statistical analysis}

Statistical analysis was performed with IBM SPSS Statistic (IBM SPSS Statistic version 27.0 lnk IBM Corporation and its licensor 1989-2020) and GraphPad Prism 9. A sample size of 58 for each group at study achieved $90 \%$ power to detect a $15 \%$ difference among the means versus the alternative of equal means using an $\mathrm{F}$ test at a 0.05 significance level. The size of the variation in the means is represented by 0.25 of their standard deviation. Continuous variables were presented as mean \pm standard deviation, ordinal variables as median and interquartile range (IQR), and categorical variables as percentage. MannWhitney and chi-square test were used for multiple comparisons. A two-factor ANOVA for repeated measures was performed in order to evaluate the difference in means between patients receiving vitamin D supplementation and counterparts during the followup. Tests were performed considering a level of significance of $5 \%$.

\section{Results}

Overall, 140 patients were included in the study (Figure 1), 69 patients receiving cholecalciferol (56.5\% women, mean age $84.9 \pm 6.4$ years) and 71 in therapy with calcifediol (59.1\% 
women, mean age $82.7 \pm 6.7$ years). As reported in Table 1 , the two groups did not differ in terms of degree of disability [ADL median (IQR): $5(2)$ vs 6(1), $\mathrm{p}=0.42$; IADL median (IQR): 4(5) vs 5(4), $\mathrm{p}=0.42$ ], nutritional status [BMI median (IQR): 23.7(7.2) vs 25(5.6), $\mathrm{p}=$ 0.95 , MNA median (IQR): 23(8) vs 25(6), $\mathrm{p}=0.55$ ] and strength estimated through the HGS test (mean $17.5 \pm 7.2$ vs $17.3 \pm 7.2, \mathrm{p}=0.92$ ). No statistical differences were found at Spearman's correlation analysis between HG test and 25OHD (Spearman's rho $=0.50, \mathrm{p}=0.30$ ). Moreover, patients showed similar frailty degree as expressed using the MPI (mean 0.39 \pm 0.20 vs $0.32 \pm 0.18, p=0.37$ ). As regards to biochemistry blood exams, no differences were found in terms of serum creatinine concentration $(1.15 \pm 0.92$ vs $1.21 \pm 1.02 \mathrm{mg} / \mathrm{dL}, \mathrm{p}$ $=0.24)$, PTH circulating levels $(48.1 \pm 39.6$ vs $60.7 \pm 36.9 \mathrm{pg} / \mathrm{mL}, \mathrm{p}=0.17)$, calcium concentration $(8.8 \pm 0.4$ vs $9 \pm 0.4 \mathrm{mg} / \mathrm{dL}, \mathrm{p}=0.052)$, phosphoremia $(3.2 \pm 0.5$ vs $3.3 \pm 0.8 \mathrm{mg} / \mathrm{dL}, \mathrm{p}$ $=0.35)$ and albumin concentration $(3.5 \pm 0.4$ vs $3.5 \pm 0.4 \mathrm{~g} / \mathrm{dL}, \mathrm{p}=0.64)$.

The mean plasma values of $25 \mathrm{OH}-\mathrm{Vitamin}$ D3 found at the enrollment were $16.8 \pm 9.9$ $\mathrm{ng} / \mathrm{mL}$ in patients receiving cholecalciferol and $18.8 \pm 13.3 \mathrm{ng} / \mathrm{mL}$ in those treated with calcifediol ( $\mathrm{p}=0.31$ ). At the 3-month follow up, the mean concentration of $25 \mathrm{OH}-\mathrm{Vitamin}$ D3 was significantly higher in patients treated with calcifediol than in patients treated with cholecalciferol (respectively, $30.7 \pm 8.4$ vs $45.4 \pm 9.8 \mathrm{ng} / \mathrm{mL}, \mathrm{p}<0.0001$ ) (Figure 2).

\section{Discussion}

In the present study we found that weekly supplementation with calcifediol appears to be more effective as compared to a bioequivalent dosage of cholecalciferol in our cohort of older adults. Several studies confirmed that calcifediol is faster and more potent than cholecalciferol in increasing plasma 25OHD levels [17-24]; still, most of these trials excluded the oldest old.

The goal of the prevention and correction of hypovitaminosis $\mathrm{D}$ is to achieve serum levels of $25 \mathrm{OHD} \geq 30 \mathrm{ng} / \mathrm{ml}(75 \mathrm{nmol} / \mathrm{L})$, as recommended by most scientific societies [1]. The main component of the daily requirement of vitamin D derives from the endogenous synthesis in the skin following exposure to the sun by UVB rays. However, the latter process becomes ineffective with increasing age. The most used therapeutic strategy in order to reach adequate levels of vitamin $\mathrm{D}$ is administering vitamin $\mathrm{D}$ supplements, associated with a correct daily intake of calcium, the latter preferably with food [4]. Yet, hypovitaminosis D is frequent in the oldest-old patients [1]; as reported in the literature, low muscle strength, vitamin D deficiency, and polypharmacy are all linked to greater vulnerability and frailty among older people [2]. As a fact, 25OHD is able to regulate the inflammatory response, promoting the cyclin-dependent kinase (CDK) inhibitor synthesis, influencing several growth factors, and leading to the containment of systemic inflammation [25-27]. In a condition of 25OHD deficiency, the low calcium concentration induces an increase in parathormone $(\mathrm{PTH})$, which, through considerable renal reabsorption, increase in 1,25OHD production, and interaction with RANKL, restores the serum calcium values [28-30]. One of the strengths of the current study was that mean age of patients was significantly higher compared to previous reports [17-23]; furthermore, we investigated functional status, reporting a high degree of autonomy in ADL in both groups. At baseline, no differences between the two cohorts were found in terms of BMI and MNA, confirming the homogeneity of our sample [24]. Although not statistically significant, the higher $25 \mathrm{OHD}$, the higher values at Handgrip test, thus highlighting the relation between 25OHD and muscle function [31-33].

At the 3-month follow up, both cholecalciferol and calcifediol supplementation resulted effective to accomplish the $30 \mathrm{ng} / \mathrm{mL}$ threshold of hypovitaminosis D. The mean concentration of $25 \mathrm{OH}-$ Vitamin D3 was significantly higher in patients treated with calcifediol than in patients treated with cholecalciferol, further strengthening literature data [4,1724]. These findings can be explained by the different intestinal absorption kinetics in older 
patients. Indeed, cholecalciferol is transported by chylomicrons and reaches the bloodstream via the lymphatic circulation [34,35] calcifediol is absorbed very effectively (almost $100 \%)$, as it is transported directly into the bloodstream via the portal vein [36]. Furthermore, since calcifediol does not require hepatic conversion, it shows a linear relationship between the dose administered and serum levels achieved [23]. Therefore, it is widely reported that supplementation with cholecalciferol is effective in healthy subjects with hypovitaminosis $\mathrm{D}$, whereas in patients with intestinal malabsorption could be less useful at achieving the supplementation threshold. The older patient frequently experiences symptoms and signs of intestinal malabsorption, due to polypharmacology, and gut dysbiosis caused by drugs interaction and pathophysiological ageing of gastrointestinal tract $[37,38]$. In conclusion, the present study confirms previous findings and provides additional evidence on the oldest old, usually under-represented in clinical trials. Nonetheless, our study has some limitations. Participants assumed both the vitamin D supplementations at home, in absence of an investigator confirmation; thus, an intention-to-treat analysis was performed, being an exact measure of treatment adherence not feasible. However, results from our study are superimposable with previous reports carried in similar cohort of older patients, underlying the reliability of our findings.

\section{Conclusions}

This study documents how 3 months of supplementation with cholecalciferol or calcifediol results in both cases effective in reaching optimal circulating values of $25 \mathrm{OH}$-VitaminD3 in the elderly patient suffering from hypovitaminosis D. However, supplementation with calcifediol allows obtaining average circulating values of $25 \mathrm{OH}-\mathrm{VitaminD} 3$ significantly higher (over 50\%) than those obtained with cholecalciferol. Further, larger, multi-center studies are needed to confirm these findings.

Supplementary Materials: The following are available online at www.mdpi.com/xxx/s1, Figure 1: Flowchart of study enrollment. Table 1. Clinical characteristics of study population. Figure 2. Mean values of serum levels of $25(\mathrm{OH}) \mathrm{D}$ over time among patients according to the type of vitamin $\mathrm{D}$ supplementation

Author Contributions: Conceptualization, C.O., V.C., F.N. and F.M.; methodology, C.O. and F.M.; validation, C.O., V.C. and F.M.; formal analysis, C.O.; data curation, G.C. and V.M.; writing-original draft preparation, R.F., S.R and F.N.; writing - review and editing, C.O., V.C., A.M.C.; supervision, N.C., F.M.; project administration, C.O., V.C and F.M. All authors have read and agreed to the published version of the manuscript.

Funding: This research received no external funding.

Institutional Review Board Statement: The study was conducted according to the guidelines of the Declaration of Helsinki, and approved by the Tuscany Regional Ethical Committee for Clinical Sperimentation ( $\mathrm{n}^{\circ}$ protocol: CEAVNO-881/2020)

Informed Consent Statement: Informed consent was obtained from all subjects involved in the study.

Data Availability Statement: The data presented in this study are available on request from the corresponding author.

Conflicts of Interest: The authors declare no conflict of interest. 


\section{References}

1. J H, A F, R H, et al. A systematic review of vitamin D status in populations worldwide. Br J Nutr. 2014;111(1):23-45. doi:10.1017/S0007114513001840

2. MF H. Vitamin D deficiency. N Engl J Med. 2007;357(3):266-281. doi:10.1056/NEJMRA070553

3. R B, G C, L V, et al. Vitamin D and human health: lessons from vitamin D receptor null mice. Endocr Rev. 2008;29(6):726776. doi:10.1210/ER.2008-0004

4. JM Q-G, R B. Is calcifediol better than cholecalciferol for vitamin D supplementation? Osteoporos Int. 2018;29(8):16971711. doi:10.1007/S00198-018-4520-Y

5. $\quad$ PA P, PD T, IR K, MP L. Validation of the Cumulative Illness Rating Scale in a geriatric residential population. $J$ Am Geriatr Soc. 1995;43(2):130-137. doi:10.1111/J.1532-5415.1995.TB06377.X

6. S K, AB F, RW M, BA J, MW J. STUDIES OF ILLNESS IN THE AGED. THE INDEX OF ADL: A STANDARDIZED MEASURE OF BIOLOGICAL AND PSYCHOSOCIAL FUNCTION. JAMA. 1963;185(12):914-919. doi:10.1001/JAMA.1963.03060120024016

7. Lawton MP, Brody EM. Assessment of Older People: Self-Maintaining and Instrumental Activities of Daily Living. Gerontologist. 1969;9(3_Part_1):179-186. doi:10.1093/GERONT/9.3_PART_1.179

8. E P. A short portable mental status questionnaire for the assessment of organic brain deficit in elderly patients. $J \mathrm{Am}$ Geriatr Soc. 1975;23(10):433-441. doi:10.1111/J.1532-5415.1975.TB00927.X

9. Y G, B V, PJ G. Assessing the nutritional status of the elderly: The Mini Nutritional Assessment as part of the geriatric evaluation. Nutr Rev. 1996;54(1 Pt 2). doi:10.1111/J.1753-4887.1996.TB03793.X

10. M R Bliss, R McLaren ANE-S. Mattresses for preventing pressure sores in geriatric patients. Mon Bull Minist Heal Public Heal Lab Serv. 1966;25(238-68).

11. A P, F R, N M, et al. Comparing the prognostic accuracy for all-cause mortality of frailty instruments: a multicentre 1year follow-up in hospitalized older patients. PLoS One. 2012;7(1). doi:10.1371/JOURNAL.PONE.0029090

12. Calcium I of M (US) C to RDRI for VD and, Ross AC, Taylor CL, Yaktine AL, Valle HB Del. Dietary Reference Intakes for Calcium and Vitamin D. Diet Ref Intakes Calcium Vitam D. Published online 30 March 2011. doi:10.17226/13050

13. Veleva BI, Chel VG, Achterberg WP. Efficacy of daily 800 IU vitamin D supplementation in reaching vitamin D sufficiency in nursing home residents: cross-sectional patient file study. BMC Geriatr 2014 141. 2014;14(1):1-7. doi:10.1186/1471-231814-103

14. Cosman F, Beur SJ de, LeBoff MS, et al. Clinician's Guide to Prevention and Treatment of Osteoporosis. Osteoporos Int. 2014;25(10):2359. doi:10.1007/S00198-014-2794-2

15. HA B-F, WC W, EJ O, et al. A pooled analysis of vitamin D dose requirements for fracture prevention. $N$ Engl J Med. 2012;367(1):40-49. doi:10.1056/NEJMOA1109617

16. Bischoff-Ferrari HA, Willett WC, Wong JB, et al. Prevention of Nonvertebral Fractures With Oral Vitamin D and Dose Dependency: A Meta-analysis of Randomized Controlled Trials. Arch Intern Med. 2009;169(6):551-561. doi:10.1001/ARCHINTERNMED.2008.600

17. Navarro-Valverde C, Sosa-Henríquez M, Alhambra-Expósito MR, Quesada-Gómez JM. Vitamin D3 and calcidiol are not equipotent. J Steroid Biochem Mol Biol. 2016;164:205-208. doi:10.1016/J.JSBMB.2016.01.014

18. Jetter A, Egli A, Dawson-Hughes B, et al. Pharmacokinetics of oral vitamin D 3 and calcifediol ir. Bone. 2014;59:14-19. doi:10.1016/j.bone.2013.10.014

19. A S, C M, RF C, et al. Effects of Cholecalciferol vs Calcifediol on Total and Free 25-Hydroxyvitamin D and Parathyroid Hormone. J Clin Endocrinol Metab. 2017;102(4):1133-1140. doi:10.1210/JC.2016-3919

20. HA B-F, B D-H, E S, et al. Oral supplementation with 25(OH)D3 versus vitamin D3: effects on 25(OH)D levels, lower extremity function, blood pressure, and markers of innate immunity. J Bone Miner Res. 2012;27(1):160-169. doi:10.1002/JBMR.551 21. MJ B-L, RP H, S D, TC C, MF H. Vitamin D and its major metabolites: serum levels after graded oral dosing in healthy men. Osteoporos Int. 1998;8(3):222-230. doi:10.1007/S001980050058

22. KD C, KM S, AJ L, et al. Relative effectiveness of oral 25-hydroxyvitamin D3 and vitamin D3 in raising wintertime serum 25-hydroxyvitamin D in older adults. Am J Clin Nutr. 2012;95(6):1350-1356. doi:10.3945/AJCN.111.031427

23. AMM V, M T, MF de R, J W, LJC van L, LCPGM de G. Dose-response effects of supplementation with calcifediol on serum 25-hydroxyvitamin D status and its metabolites: A randomized controlled trial in older adults. Clin Nutr. 2018;37(3):808-814. doi:10.1016/J.CLNU.2017.03.029

24. Ruggiero C, Baroni M, Bini V, et al. Effects of Weekly Supplementation of Cholecalciferol and Calcifediol Among the Oldest-Old People: Findings From a Randomized Pragmatic Clinical Trial. Nutrients. 2019;11(11). doi:10.3390/NU11112778

25. Liu N, Su H, Zhang Y, Kong J. The protective effect of 1,25(OH)2D3 against cardiac hypertrophy is mediated by the cyclin-dependent kinase inhibitor p21. Eur J Pharmacol. 2020;888:173510. doi:10.1016/J.EJPHAR.2020.173510

26. Vanoirbeek E, Krishnan DA V, Eelen DIG, et al. The Anti-Cancer and Anti-Inflammatory Actions of 1,25(OH)2D3. Best Pract Res Clin Endocrinol Metab. 2011;25(4):593. doi:10.1016/J.BEEM.2011.05.001

27. Bhoora S, Punchoo R. Policing Cancer: Vitamin D Arrests the Cell Cycle. Int J Mol Sci. 2020;21(23):1-20. doi:10.3390/IJMS21239296 
28. AG T, MA H, HA M, GJ A, PH A. The local production of 1,25(OH)2D3 promotes osteoblast and osteocyte maturation. J Steroid Biochem Mol Biol. 2014;144 Pt A(PART A):114-118. doi:10.1016/J.JSBMB.2013.10.003

29. Pike JW, Christakos S. Biology and Mechanisms of Action of the Vitamin D Hormone. Endocrinol Metab Clin North Am. 2017;46(4):815. doi:10.1016/J.ECL.2017.07.001

30. Bikle DD. Vitamin D and Bone. Curr Osteoporos Rep. 2012;10(2):151. doi:10.1007/S11914-012-0098-Z

31. C EH, S F, JM C, Y B, S W. Vitamin D supplementation and muscle strength in pre-sarcopenic elderly Lebanese people: a randomized controlled trial. Arch Osteoporos. 2018;14(1). doi:10.1007/S11657-018-0553-2

32. P M, P Y, A T, et al. Vitamin D Supplementation Improves Quality of Life and Physical Performance in Osteoarthritis Patients. Nutrients. 2017;9(8). doi:10.3390/NU9080799

33. B D-H. Vitamin D and muscle function. J Steroid Biochem Mol Biol. 2017;173:313-316. doi:10.1016/J.JSBMB.2017.03.018

34. GR T, B L, CC B. Absorption of vitamin D3-3H in control subjects and patients with intestinal malabsorption. J Clin Invest. 1966;45(1):94-102. doi:10.1172/JCI105327

35. Davies M, Mawer EB, Krawitt EL. Comparative absorption of vitamin D3 and 25-hydroxyvitamin D3 in intestinal disease. Gut. 1980;21(4):287-292. doi:10.1136/gut.21.4.287

36. M Maislos, J Silver MF. Intestinal absorption of vitamin D sterols: differential absorption into lymph and portal blood in the rat. Gastroenterology. 1981;80(6)(1528-34).

37. PR H. Intestinal malabsorption in the elderly. Dig Dis. 2007;25(2):144-150. doi:10.1159/000099479

38. LR S. Maldigestion Versus Malabsorption in the Elderly. Curr Gastroenterol Rep. 2020;22(7). doi:10.1007/S11894-02000771-5

Table 1. Clinical characteristics of study population

\begin{tabular}{|c|c|c|c|c|}
\hline & $\begin{array}{l}\text { All patients } \\
\qquad \mathrm{N}=140\end{array}$ & $\begin{array}{l}\text { Cholecalciferol } \\
\qquad N=69\end{array}$ & $\begin{array}{l}\text { Calcifediol } \\
\qquad N=71\end{array}$ & $\mathrm{p}$-value \\
\hline Female (\%) & $81(57.8)$ & $39(56.5)$ & $42(59.1)$ & 0.75 \\
\hline Age y, (mean, sd) & 83.8(6.6) & $84.9(6.4)$ & $82.7(6.7)$ & 0.052 \\
\hline BMI (median, IQR) & $24.4(6.1)$ & 23.7(7.2) & $25(5.6)$ & 0.95 \\
\hline ADL (median, IQR) & $6(2)$ & $5(2)$ & $6(1)$ & 0.42 \\
\hline IADL (median, IQR) & $4(5)$ & $4(5)$ & $5(4)$ & 0.42 \\
\hline MNA (median, IQR) & $25(5)$ & $23(8)$ & $25(6)$ & 0.55 \\
\hline $\begin{array}{l}\text { Exton Smith Scale (median, } \\
\qquad \mathrm{IQR})\end{array}$ & $18(3)$ & $17(3)$ & $18(3)$ & 0.74 \\
\hline SPMSQ (median, IQR) & $2(2)$ & $2(2)$ & $2(3)$ & 0.68 \\
\hline CIRS - c (median, IQR) & $3(2)$ & $3(2)$ & $3(3)$ & 0.37 \\
\hline MPI (mean, sd) & $0.35(0.19)$ & $0.39(0.20)$ & $0.32(0.18)$ & 0.37 \\
\hline $\begin{array}{l}\text { Creatinine } \mathrm{mg} / \mathrm{dl} \text { (mean, } \\
\text { sd) }\end{array}$ & $1.15(0.53)$ & $1.15(0.92)$ & $1.21(1.02)$ & 0.24 \\
\hline PTH ng/dL (mean, sd) & $55.3(38.3)$ & 48.1(39.6) & $60.7(36.9)$ & 0.17 \\
\hline $\begin{array}{l}\text { Serum Calcium mg/dl } \\
\text { (mean, sd) }\end{array}$ & $8.9(0.4)$ & $8.8(0.4)$ & $9.0(0.4)$ & 0.052 \\
\hline $\begin{array}{l}\text { Serum Phosphate mg/dl } \\
\text { (mean, sd) }\end{array}$ & $3.25(0.8)$ & $3.2(0.5)$ & $3.3(0.8)$ & 0.35 \\
\hline $\begin{array}{l}\text { Serum Albumin g/dl (mean, } \\
\text { sd) }\end{array}$ & $3.5(0.4)$ & $3.5(0.4)$ & $3.5(0.4)$ & 0.64 \\
\hline Handgrip test (mean, sd) & $17.4(7.4)$ & $17.5(7.2)$ & $17.3(7.2)$ & 0.92 \\
\hline Males & $25.9(5.7)$ & $24.3(5.4)$ & $27.1(6,2)$ & 0.34 \\
\hline Females & $13.9(4.8)$ & $13.7(4.4)$ & $14.1(5.3)$ & 0.82 \\
\hline
\end{tabular}




$\begin{array}{ccccc}\begin{array}{c}25 \text { OHVitD at study } \\ \text { enrollment }\end{array} & 17.8(11.7) & 16.8(9.9) & 18.8(13.3) & 0.31 \\ 25 \text { OHVitD at } 3 \text { months } & 38.1(18.3) & 30.7(8.4) & 45.4(9.8) & <\mathbf{0 . 0 0 1} \\ \quad \text { follow-up } & & & \\ 25 \text { OH D3 mean difference } & 20.2(+17.8 ;+ & 13.7(+11.8 ;+15.3) & 26.6(+22.9 ;+30.1) & <\mathbf{0 . 0 0 1} \\ \text { at 3 months (SEM) } & 23.2) & & \end{array}$

BMI: Body Mass Index.; ADL: Activities of Daily Living; IADL: Instrumental Activities of Daily Living; MNA: Mini- Nutritional Assessment; SPMSQ: Short Portable Mental Status Questionnaire; CIRS-C: Cumulative Illness Rating Scale-Comorbidity; MPI: Multi Prognostic Index; PTH: Parathyroid Hormone

\section{Figure Legends:}

Figure 1. Flowchart of study enrollment

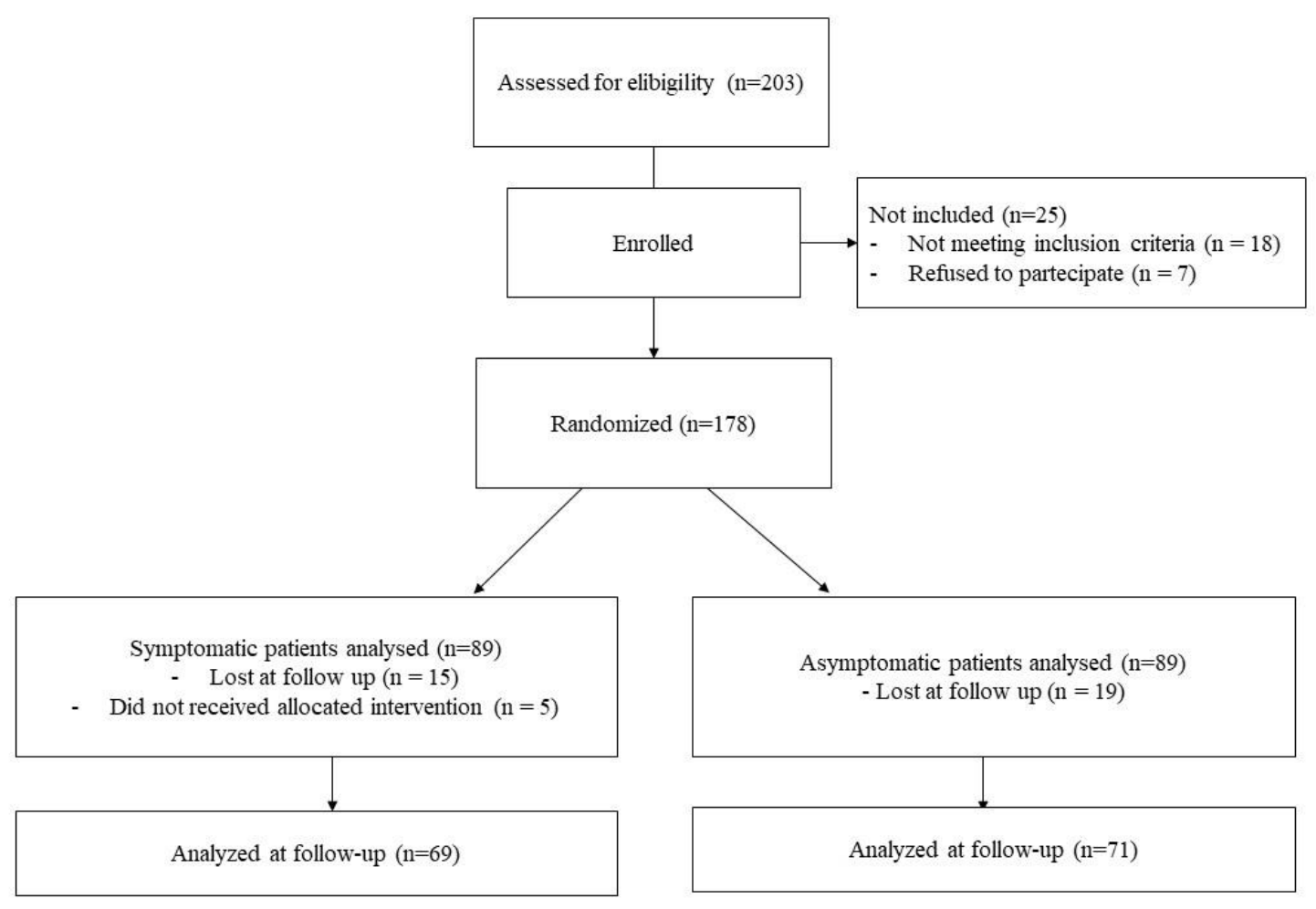

Figure 2. Mean values of serum levels of $25(\mathrm{OH}) \mathrm{D}$ over time among patients according to the type of vitamin D supplementation 


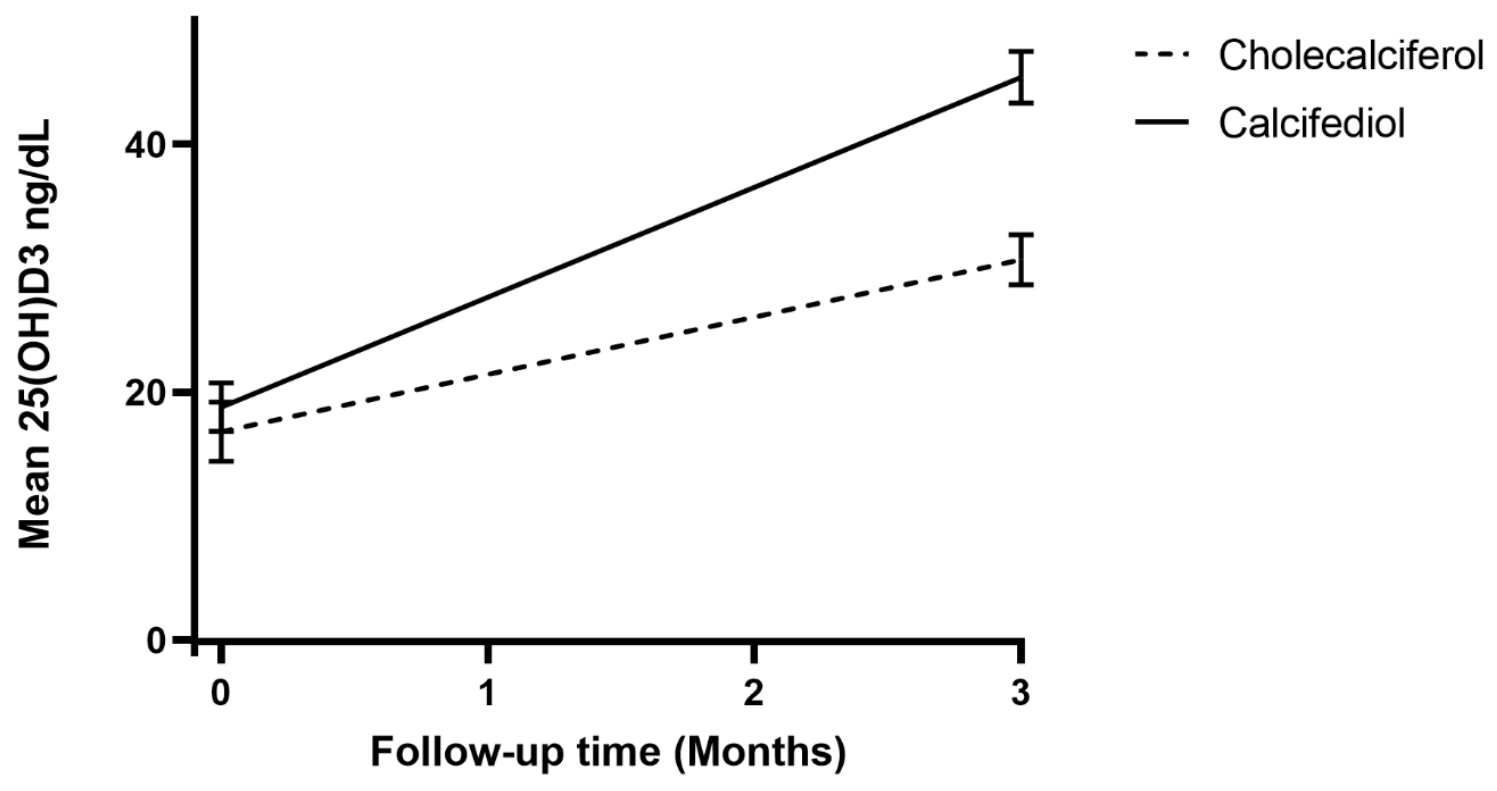

